\title{
Nonalcoholic Fatty Liver Disease: Focus on Lipoprotein and Lipid Deregulation
}

\author{
Klementina Fon Tacer and Damjana Rozman \\ Center for Functional Genomic and Biochips, Institute of Biochemistry, Faculty of Medicine, University of Ljubljana, Zaloška 4, \\ 1000 Ljubljana, Slovenia
}

Correspondence should be addressed to Damjana Rozman, damjana.rozman@mf.uni-lj.si

Received 4 January 2011; Revised 26 April 2011; Accepted 27 April 2011

Academic Editor: Shinichi Oikawa

Copyright $(92011$ K. Fon Tacer and D. Rozman. This is an open access article distributed under the Creative Commons Attribution License, which permits unrestricted use, distribution, and reproduction in any medium, provided the original work is properly cited.

\begin{abstract}
Obesity with associated comorbidities is currently a worldwide epidemic and among the most challenging health conditions in the 21st century. A major metabolic consequence of obesity is insulin resistance which underlies the pathogenesis of the metabolic syndrome. Nonalcoholic fatty liver disease (NAFLD) is the hepatic manifestation of obesity and metabolic syndrome. It comprises a disease spectrum ranging from simple steatosis (fatty liver), through nonalcoholic steatohepatitis (NASH) to fibrosis, and ultimately liver cirrhosis. Abnormality in lipid and lipoprotein metabolism accompanied by chronic inflammation is the central pathway for the development of metabolic syndrome-related diseases, such as atherosclerosis, cardiovascular disease (CVD), and NAFLD. This paper focuses on pathogenic aspect of lipid and lipoprotein metabolism in NAFLD and the relevant mouse models of this complex multifactorial disease.
\end{abstract}

\section{Introduction}

Nonalcoholic fatty liver disease (NAFLD) is progressively diagnosed worldwide and is considered to be the most common liver disorder in Western countries, estimated to affect at least one-quarter of the general population $[1,2]$. NAFLD used to be almost exclusively a disease of adults but is now becoming a significant health issue also in obese children. The prevalence of childhood obesity has significantly increased over the past three decades $[3,4]$ and boosted the prevalence of NAFLD in adolescents (reviewed in [5]).

NAFLD covers a spectrum of hepatic pathologies, ranging from simple steatosis to nonalcoholic steatohepatitis (NASH). It strongly associates with obesity, insulin resistance, hypertension, and dyslipidaemia and is now regarded as the liver manifestation of metabolic syndrome [6]. Simple steatosis is largely benign and nonprogressive whereas NASH is characterized by hepatocyte injury, inflammation, and fibrosis and can lead to cirrhosis, liver failure, and hepatocellular carcinoma [7].

Lipid accumulation in the liver is the major hallmark of NAFLD. A comprehensive understanding of the mechanisms leading to liver steatosis and further transition to nonalcoholic steatohepatitis (NASH) still remains elusive. There is no simple solution to understand the multi-factorial nature of NAFLD appearance and progression, presumably due to the nonlinear interactions of those factors. Abnormalities in lipid and lipoprotein metabolism accompanied by chronic inflammation are considered to be the central pathway for the development of several obesity-related co-morbidities such as NAFLD and cardio-vascular disease (CVD) $[8,9]$.

NAFLD is not an innocent bystander in the metabolic syndrome. Rather, it represents an important self-governing risk for the development of CVD. In NAFLD patients, liver overproduces several atherogenic factors, such as cytokines and "bad" lipoproteins. In this manner, fatty liver is associated with increased serum low-density lipoproteins (LDL) and triglycerides, combined with decreased highdensity lipoproteins (HDL) that represent a threat for CVD development (reviewed in [10]). There are many evidences suggesting that NAFLD is linked to the increased incidence of CVD, both in nondiabetic and type 2 diabetic patients [11]. Furthermore, a prospective observational study of Hamaguchi et al. implied that NAFLD may play a central role in the cardiovascular risk of metabolic syndrome [12]. 
NAFLD is also very common in type 1 diabetes and is strongly associated with increased prevalence of CVD independent of other confounding factors [13]. In addition to the liver-related causes, CVD represents the major survival risk of patients with NASH [14]. However, the nature of the relationship NAFLD/CVD is still under debate. McKimmie and coauthors [15] did not find independent association between hepatic steatosis and CVD in a subset of participants in Diabetes Heart Study. They suggested that hepatic steatosis is more a secondary phenomenon than a direct mediator of CVD. Even so, sufficient evidence exists that CVD risk assessment seems mandatory in NAFLD patients.

NAFLD pathogenesis as a two-hit model was initially proposed by Day and James [16]. First, insulin resistance causes lipid accumulation in hepatocytes; second, cellular insults such as oxidative stress, lipid oxidation, and inflammation result in NASH. Deregulation of fat metabolism in the fatty liver is accompanied by overproduction of very-lowdensity lipoproteins (VLDL), the characteristic lipoproteins of the metabolic syndrome [17]. LDL has recently attracted attention since small, dense LDL is the most atherogenic subclass of LDL, and this subclass is elevated in metabolic syndrome and fatty liver. However, elevated VLDL is likely the key metabolic disturbance and correlates strongly with obesity and metabolic syndrome. Fatty liver-associated dyslipidemic profile characterized by large VLDL, small dense LDL, and decreased large HDL correlates with the intrahepatic lipid content. Herein, we review recent understanding of lipid and lipoprotein homeostasis in the development of NAFLD and the relevant polygenic mouse mode that help in unraveling the pathogenesis of this disease. The studies included in this review paper (31 clinical and 82 experimental studies) were selected based on the involvement in lipid and lipoprotein metabolism and reported association with NAFLD and insulin resistance. Major pathways of lipid and lipoprotein homeostasis relevant for the development of NAFLD are depicted in Figure 1. Figure 2 summarizes the association between insulin resistance-induced lipid abnormalities and pathogenesis of NAFLD. Table 1 recapitulates the physiologic role of all receptors and enzymes described in the paper and the association with insulin resistance and the pathogenesis of NAFLD. Finally, we briefly discuss how reviewed pathways are involved in the therapeutic strategies for NAFLD.

\section{Lipoprotein Metabolism in NAFLD}

Lipid transport in plasma utilizes highly specialized lipoprotein complexes. After a meal, dietary fat and cholesterol are absorbed into intestinal cells and incorporated in nascent chylomicrons. The liver is another important source of lipoproteins. A central metabolic role of the liver is to maintain plasma glucose within narrow physiological limits regardless of the nutritional state of the animal. In energy excess, glucose is converted to fatty acids, which are further used to synthesize triglycerides. Triglycerides can be stored as lipid droplets within hepatocytes or incorporated into very-low-density lipoproteins (VLDL) and secreted into the blood. Once in the blood, triglyceride content of these particles is progressively reduced by the action of lipoprotein lipase (LPL), eventually resulting in intermediate-density lipoproteins (IDLs) and low-density lipoproteins (LDL) with relatively high cholesterol content [69]. LDL circulates and is absorbed by the liver by binding of LDL to LDL receptor [70].

Patients with insulin resistance increase VLDL secretion as they attempt to maintain hepatic lipid homeostasis. Therefore, insulin resistance is associated with abnormal concentration of lipoproteins [71, 72], elevated VLDL production, and increase in plasma LDL [73]. Elevated plasma LDL was also found in patients with NAFLD $[5,74]$.

Association of fatty liver and small dense LDL (sdLDL) concentration is now well documented $[75,76]$. As the triglyceride-rich VLDL is entering plasma at an accelerated rate, small, dense LDL, the most atherogenic subclass of LDL, develop after triglycerides are gradually removed from LDL. Two enzymes are implicated in this process. First, cholesteryl ester transfer protein (CETP) [18] facilitates the transfer of triglycerides from VLDL to LDL (and cholesteryl esters from LDL to VLDL), and, second, hepatic lipase increases lipolysis of triglyceride-rich LDL resulting in the formation of sdLDL [21]. Thus, CETP remodels VLDL in circulation, enriches it in cholesterol, and also favors, together with HL, the formation of sdLDL. CETP activity is increased in hepatic steatosis patients [19]. LDL receptor shows a lower affinity for smaller particles, therefore such particles stay longer in the circulation [77]. Hyperlipidemia can be further exacerbated by low activity of lipoprotein lipase, or by high level of apolipoprotein C-3 (APOC-3), an inhibitor of lipoprotein lipase. Indeed, APOC-3 polymorphisms have been associated with fatty liver in humans [20]. However, this association was not found in recent Dallas Heart Study [22].

In contrast to simple steatosis, the steatohepatitis links to dysfunctional VLDL synthesis and secretion [78]. Fujita et al. [78] investigated the difference in lipid metabolite and serum lipoprotein levels between patients with steatosis or NASH. Hepatic lipid profiles in the two patient groups were similar; however, VLDL synthesis and export were impaired in NASH. This is in line with the two main experimental animal models that are often used to study NAFLD [79]. A high-fat/high-calorie diet is a generalized fatty liver model [79]. A choline-deficient/1-amino acid-defined (CDAA) diet, which disturbs VLDL secretion is an NASH model [80]. The former involves only fatty liver whereas the latter includes also steatohepatitis and liver cirrhosis [81].

The blockade of hepatic VLDL secretion results in accumulation of triglycerides in the liver. Microsomal triglyceride transfer protein (MTTP) is essential for the formation of VLDL in the liver [24]. Mice that cannot secrete VLDL due to the conditional knockout of Mttp in the liver exhibit markedly reduced levels of triglycerides in the plasma and develop hepatic steatosis [82, 83], however, without insulin resistance and inflammation [84]. In line with the rodent data, human MTTP polymorphisms lead to decreased MTTP activity and VLDL export and are associated with greater intracellular triglyceride accumulation. Altogether, this impacts NASH pathogenesis [25], possibly through 


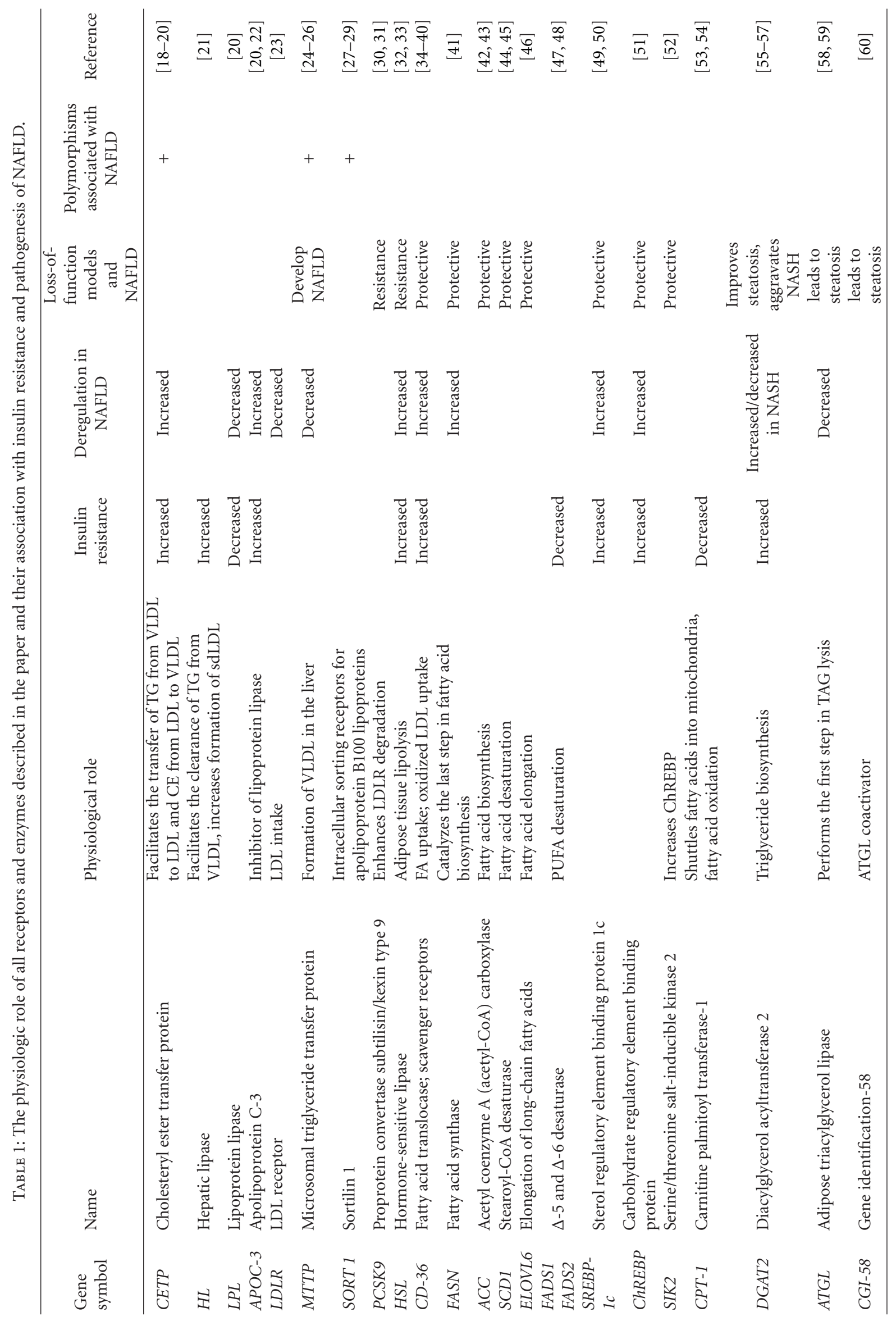




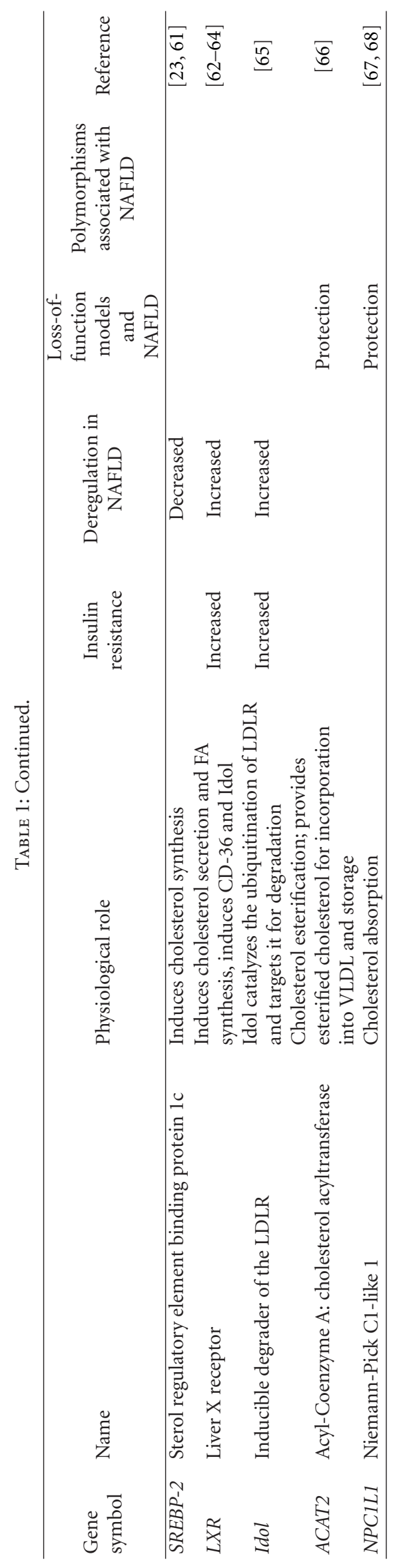




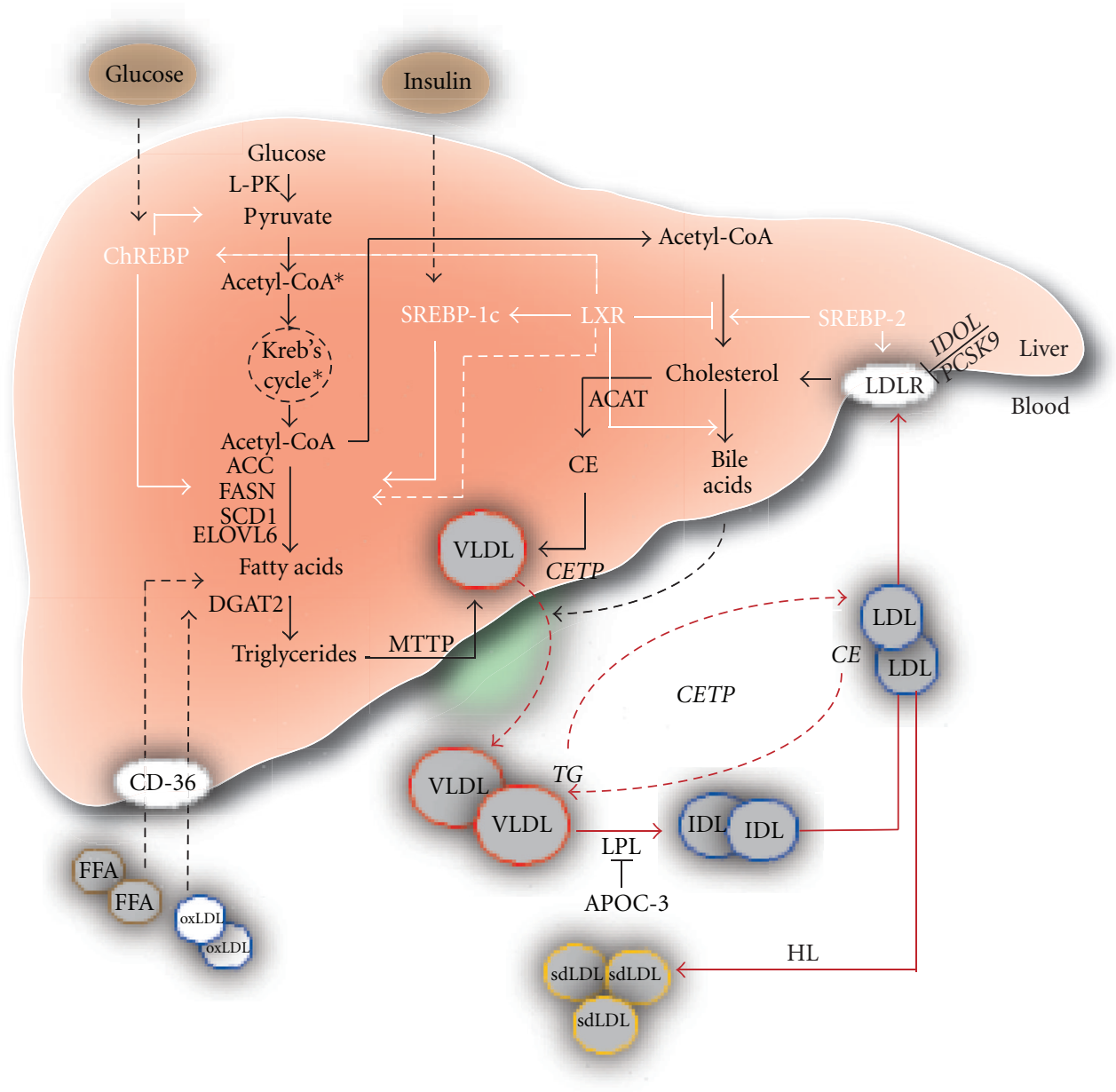

FIGURE 1: Lipid and lipoprotein pathways in the pathogenesis of NAFLD. NAFLD is considered to be liver manifestation of obesity and metabolic syndrome. In response to insulin and glucose, transcription factors SREBPs and ChREBP are activated and induce the expression of genes involved in the synthesis of fatty acids and cholesterol in the liver. Enhanced lipogenesis leads to enhanced VLDL production, a major metabolic perturbation in NAFLD. Increased VLDL secretion in plasma results in increase in LDL through CETP-mediated exchange of cholesteryl esters and triglycerides between LDL and VLDL, followed by triglyceride removal from LDL by hepatic lipase (HL). Liver removes LDL from circulation by LDLR-mediated endocytosis. Oxidized LDL and FFA are transported to the liver by CD-36, FA translocase, and scavenger receptor. Italics: metabolic genes, black lines: metabolic pathways, black dash lines: coming out or in the liver, white lines: transcriptional regulation, * process in the mitochondria.

modulating postprandial lipid profile [26]. On the other hand, a high-fat diet was shown to induce the methylation of MTTP and consequently reduce its mRNA level [85]. The postprandial phase has been linked to increased oxidative stress [86], and increased lipid peroxidation is implicated in NASH pathogenesis. Oxidized LDL can activate hepatic stellate cells that are crucial in NASH pathogenesis [87].

Sortilins, intracellular sorting receptors for apolipoprotein B 100 (APO-B 100), are new players in lipoprotein metabolism. Genome-wide association studies (GWAS) of common genetic variations associated sortilin 1 (Sort 1) gene with LDL metabolism. Several findings provide evidences that sortilin 1 is involved in the hepatic metabolism of lipoproteins containing APO-B, although the precise mechanism waits for further elucidation. Kjolby et al. showed that Sort 1 interacts with APO-B 100 in the Golgi and facilitates the formation and hepatic export of VLDL lipoproteins, thereby regulating plasma LDL concentration. They showed that Sort 1 overexpression stimulated hepatic release of lipoproteins and increased plasma LDL [27]. Using different mouse models, Musunuru et al. [28] showed an inverse relationship between Sort1 1 expression and circulating LDL cholesterol. Namely, liver-specific overexpression of Sort 1 in mice decreased serum LDL cholesterol whereas knockdown had opposite effect. Moreover, Linsel-Nitschke showed that Sort 1 enhanced LDL endocytosis [29]. Further studies are needed to understand the mechanistic link between sortilin 1 and lipoprotein metabolism.

Plasma levels of LDL, the major cholesterol carrying lipoprotein in humans, are determined by the relative rates of production and clearance by LDL receptor. The groundbreaking work of Goldstein and Brown defined the pathway of LDL receptor-mediated endocytosis and its regulation by cholesterol-dependent negative feedback 


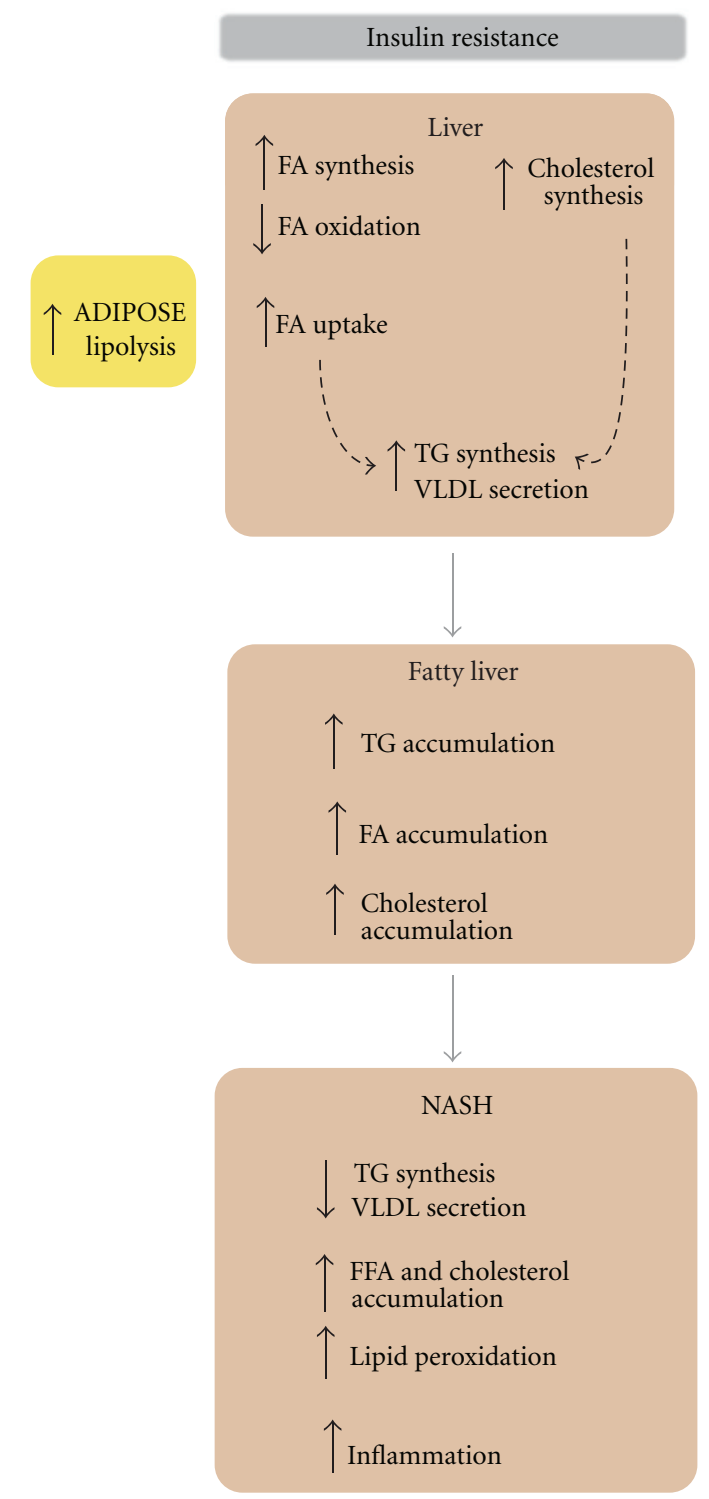

Figure 2: Summary of insulin resistance-induced lipid abnormalities and consequent pathogenesis of NAFLD. In an insulin resistant setting, insulin is unable to inhibit lipolysis in adipose tissue leading to overflow of free FA into the bloodstream and in the liver. In the liver, hyperinsulinemia and hyperglycemia induce the synthesis of fatty acid and cholesterol which results in increased triglyceride synthesis and VLDL assembly and secretion. Since triglyceride synthesis prevails over VLDL secretion, excess triglycerides accumulate and lead to fatty liver development. In $\mathrm{NASH}$, triglyceride synthesis and VLDL assembly is impaired and free FA and cholesterol accumulate. Increased lipid accumulation leads to lipid peroxidation and inflammation which exacerbates liver damage.

transcriptional regulation (reviewed in [88]). In addition to transcriptional regulation, LDLR is also regulated on the protein level. PCSK9 (proprotein convertase subtilisin/ kexin type 9) enhances LDLR degradation, resulting in low-density lipoprotein accumulation in plasma. PCSK9 binds the EGF-A domain of the low-density lipoprotein receptor (LDLR) and favors the targeting of the LDLR to endosomes/lysosomes and its degradation (reviewed in [30]). Individuals with loss-of-function mutations in PCSK9 have reduced plasma levels of LDL cholesterol and are protected from CHD [89]. Inhibiting the action of PCSK9 on the LDLR has emerged as a novel therapeutic target for hypercholesterolemia. It was shown recently that PCSK9 deficiency confers resistance to liver steatosis; however, this effect seemed to be LDLR independent [31].

\section{Cholesterol and Triglyceride Homeostasis in NAFLD}

Abnormal lipoprotein concentration in plasma reflects disturbances in homeostasis of major lipid components of lipoproteins, triglycerides, cholesterol, and cholesterol esters. Excessive accumulation of triglycerides in the liver is the hallmark of NAFLD. The potential sources of fat contributing to hepatic steatosis are dietary fatty acids through uptake of intestine-borne chylomicron remnants, increased lipolysis of peripheral fat store, and de novo synthesis. Tracer studies in obese humans with NASH demonstrated that $60 \%$ of triglycerides in the liver arose from free fatty acids, $25 \%$ from de novo lipogenesis, and $15 \%$ from the diet [90].

3.1. Fatty Acids and Triglycerides. Insulin resistance is associated with deregulation of adipose-derived fatty acid flux in the fasting state [91]. In NAFLD patients, insulin does not suppress adipose tissue lipolysis to the same extent that it does in healthy individuals [32]. Studies on mice have revealed that hormone-sensitive lipase- (HSL-) knockout mice show increased insulin sensitivity with decreased hepatic triglyceride content [33]. Fatty acid uptake was believed to be predominantly passive; however, this concept has been challenged by the discovery of cluster differentiation protein-36 (CD-36), fatty acid translocase [34], and its association with NAFLD. CD-36 is regulated by insulin and can induce hepatosis [92]. In NASH, development of disease is associated with increased expression of CD-36 [35-37].

Among major causes of fat accumulation in NAFLD is the inability of the liver to regulate the changes in lipogenesis in the transition from fasted to fed state. Several studies suggested increased hepatic lipogenesis in hepatic steatosis. Increased lipogenesis may have dual effect: increased triglyceride synthesis and decreased fatty acid oxidation through production of malonyl-CoA [93], both leading to increased triglycerides content in fatty liver. Sanyal et al. reported that $\beta$-oxidation of fatty acids in the liver was increased in patients with NASH [94]. However, this increase might not sufficiently overcome the elevated rates of hepatic fatty acid synthesis.

De novo fatty acid synthesis is the metabolic pathway converting excess carbohydrates into fatty acids, which are ultimately esterified to form triglycerides. Several indications show an increase in fatty acid synthesis in NAFLD. Humans 
[95] and mice [96] with fatty liver accumulate oleic acid, the end product of fatty acid synthesis, indicating increase in this pathway. Fatty acid synthase (FASN) catalyzes the last step in fatty acid biosynthesis, and thus, it is believed to be a major determinant of the maximal hepatic capacity to generate fatty acids by de novo lipogenesis. The expression of FASN mRNA in human liver is higher in hepatic steatosis [41]. Further on, knocking down several genes of the fatty acid synthesis, desaturation, and elongation, such as $A c c, S c d 1$, and Elovl6, reversed several metabolic defects associated with hepatic steatosis in experimental animals [42-46]. NAFLD is also associated with depletion of $n-3$ polyunsaturated fatty acids (PUFA), a consequence of decreased liver $\Delta-6$ and $\Delta-5$ desaturase in obese NAFLD patients ([47], reviewed in [48]).

The mouse strain C57BL/6 is one of the most frequent laboratory strains for studies of high lipid-related metabolic disorders. The strain has a long life period and a high predisposition for development of induced hyperlipidemias. Hepatic lipid metabolic processes are circadian in this strain [97]. An 8-week hyperlipidemic diet (1.25\% cholesterol, $0.5 \%$ cholic acid, $15 \%$ fat) leads to fatty liver $[98,99]$, and a 5-week atherogenic diet to NASH [100]. This mouse strain has been successfully applied also in studies of cholesterollowering effects of atorvastatin [101].

Bübger et al. developed a unique polygenic model of NAFLD-so-called "fat" mice [102]. Genetic studies have confirmed a typical polygenic basis of this obesity [103105]. In contrast to many other animal models of obesity and NAFLD, this line develops NAFLD already on a lowto-moderate food intake, and development of later stages of NAFLD is accelerated on high-fat diet [106, 107]. Plasma and liver lipid profiles are perturbed similarly as in NAFLD patients. Liver transcriptome exhibits dramatic changes with perturbations in genes of de novo cholesterol synthesis, bile and glucose metabolism, liver receptors, and immune response [107]. This polygenic model is unique since it allows studies of the genetic and molecular mechanisms of both early hepatic fat accumulation and advanced forms of NAFLD. Other mouse models with defects in cholesterol synthesis might also represent useful tools for understanding NAFLD [108].

Insulin and glucose both drive lipogenesis [109] by respective transcription factors, SREBP-1c (sterol regulatory element binding protein 1c), and ChREBP (carbohydrate regulatory element binding protein). Hyperinsulinemia despite insulin resistance induces the expression of SREBP1c, a transcriptional activator of all lipogenic enzymes, resulting in increased rate of fatty acid synthesis $[49,50]$. Overexpression of Srebp-1c in transgenic mouse livers leads to classic fatty liver due to increased lipogenesis [110]. In contrast, inactivation of Srebp-1 gene in ob/ob mice results in 50\% reduction of triglycerides in these mice [111]. SREBP-1c also activates acetyl-coA carboxylase 2 (Acc2) [53] that produces malonyl-CoA. Increase in malonyl-CoA results in decreased fatty acid oxidation due to inhibition of carnitine palmitoyl transferase-1 (Cpt-1), which shuttles fatty acids into mitochondria [54]. Indeed, Acc2 knockout mice are resistant to obesity with increased Cpt-1 activity and consequent fatty acid oxidation [112].
In addition to insulin, glucose activates lipogenesis through transcriptional factor ChREBP. ChREBP simultaneously activates liver-type pyruvate kinase (L-PK), key regulator of glycolysis and all lipogenic genes [113, 114], including acetyl-CoA carboxylase and fatty acid synthase [115]. ChREBP gene expression and nuclear protein content are significantly increased in liver of ob/ob mice. Liverspecific inhibition of ChREBP improves hepatic steatosis and insulin resistance in ob/ob mice [51]. Bricambert et al. [52] went on and showed upstream regulation of ChREBP. Serine/threonine salt-inducible kinase 2 (SIK2) directly regulates hepatic lipogenesis through the inhibition of p300 acetylation of ChREBP, which in turn increases ChREBP-induced transcription. Inhibition of hepatic p300 thus offers a novel target for treating hepatic steatosis.

Triglyceride accumulation in hepatocytes was considered to be the major pathogenic trigger in the development of NAFLD. Diacylglycerol acyltransferase 2 (DGAT2) catalyzes the final step in hepatocyte triglyceride biosynthesis. Suppression of DGAT2 reversed diet-induced hepatic steatosis and insulin resistance [55] as well as attenuates hyperlipidemia [56]. However, recent findings suggest that triglyceride synthesis per se may not be harmful to hepatocytes. Rather, it provides a useful mechanism for buffering free fatty acid accumulation [57]. Yamaguchi et al. [57] show that inhibiting triglyceride synthesis by inhibiting DAGT2 does improve hepatic steatosis, yet it exacerbates liver damage and fibrosis in obese mice with nonalcoholic steatohepatitis. Lipotoxicity arises when hepatic triglyceride synthesis is unable to accommodate increased free fatty acid accumulation. Thus, rather than being hepato-toxic, liver triglyceride accumulation is actually hepatoprotective in obese, insulinresistant individuals.

Hepatic fatty acids are derived from several sources, including adipose tissue lipolysis, chylomicron-TAG lipolysis, and de novo lipogenesis, and can be stored as TAG in lipid droplets located within the cytosol [116]. Hepatic TAG stores are mobilized by several hepatic lipases. Adipose triacylglycerol lipase (Atgl) that selectively performs the first step in TAG in the liver is reduced in several rodent models of obesity, and Atgl ablation leads to steatosis, although increased TAG content in the hepatocytes from Atgl-deficient mice does not enhance insulin sensitivity [58, 59]. Similarly, inhibiting expression of ATGL coactivator (gene identification-58 (Cgi-58)) resulted in a large increase in hepatic TAG content, yet in a decrease in insulin resistance [60]. Further, overexpressing ATGL specifically in the liver of obese mice did decrease liver steatosis, but it only mildly enhanced liver insulin sensitivity [58], suggesting that ATGL might be a pharmacological therapeutic target for NAFLD but not type 2 diabetes.

3.2. Cholesterol and Cholesteryl Esters. Cholesterol is either synthesized de novo in the liver or delivered to the liver by lipoproteins (reviewed in [117]). The metabolism of cholesterol in NAFLD remains poorly explored. Insulin resistance is associated with increased cholesterol synthesis $[118,119]$. Recent metabolomic analysis implicated that cholesterol synthesis in NAFLD patients is increased, in 
contrast to diminished absorption of cholesterol [120]. The expression of cholestrogenic genes was also found elevated in NAFLD patients, accompanied by decreased SREBP-2 and LDLR expression [23]. In rodents, excess cholesterol intake contributes to the development of NAFLD even in the absence of obesity $[121,122]$.

Cholesterol rich-atherogenic diet induces oxidative stress and provokes inflammation. The transition towards hepatic inflammation is the key factor in NASH pathogenesis and promotes progression to liver damage. Currently, NASH is thought to develop via the "two hit" model [16]. According to this hypothesis, hepatic steatosis represents "first hit" and is still reversible. The "second hit" includes NASH progression beyond hepatic steatosis that promotes oxidative stress, inflammation, cell death, and fibrosis [93]. Marí et al. [123] provided evidence that mitochondrial loading of free cholesterol, but not free fatty acids or triglycerides, sensitizes the liver toTNF- $\alpha$-induced steatohepatitis. In line with these results, Wouters et al. [124] found that dietary cholesterol rather than lipid accumulation is an important risk factor for the progression to hepatic inflammation. High-cholesterol diet led to increased VLDL and was sufficient to cause inflammatory response in the liver. As mentioned earlier, increased VLDL and accompanied hypertriglyceridemia underlie the synthesis of small, dense LDL with lower affinity for LDL receptor. Therefore, these particles stay in circulation for longer period and are prone to oxidation [77]. Oxidized LDL can bind scavenger receptors, such as CD-36 [38-40], which are present on Kupffer cells and prompt inflammatory response.

Inflammatory cytokine TNF- $\alpha$ is overexpressed in the liver of obese mice and mediates insulin resistance $[125,126]$. Furthermore, TNF- $\alpha$ is required for the development of fatty liver and subsequent liver damage by alcohol [127, 128]. We $[129,130]$ and others have showed that TNF- $\alpha$ activates cholesterol synthesis and inhibits cholesterol elimination through bile acids, which together contribute to increase in LDL-cholesterol and reduction of HDL-cholesterol.

Cholesterol is indispensible, however, toxic in excess. Intracellular level of cholesterol is tightly regulated by a number of mechanisms that govern uptake, synthesis, catabolism, and export. Two master regulators of these pathways are the transcription factors SREBP-2 and LXR (liver X receptor). When intracellular cholesterol levels drop, SREBP-2 induces cholesterol biosynthesis and uptake [61]. In contrast, excess intracellular cholesterol inhibits SREBP-2 and activates LXR, which in turn promotes cholesterol export and elimination [62].

LXRs are nuclear receptors that control lipid metabolism. Nuclear receptors may have a crucial role in lipid-related genesis of NAFLD [131, 132]. LXRs were discovered as sterol sensors that regulate cholesterol homeostasis [63, 64]. In rodents, LXR promote cellular cholesterol efflux, transport, and excretion [133]. LXRs have emerged as promising drug targets for antiatherosclerotic therapies. However, pharmacological LXR activation also induces hepatic steatosis and promotes the secretion of VLDL particles by the liver, complicating the clinical application of LXR agonists. Namely, LXR activates SREBP-1c, a master transcriptional regulator of fatty acid synthesis $[134,135]$. Moreover, LXR has a central role in insulin-mediated activation of SREBP-1c-induced fatty acid synthesis in liver [136]. In addition, LXR can also promote lipogenesis in an SREBP-1c-independent manner [137, 138] and activate other lipogenic transcriptional factor ChREBP [139]. Further on, LXR was also shown to induce the expression of CD-36, fatty acid transporter, and scavenger receptor, suggesting another mechanism by which LXR can promote fatty liver [92]. LXR also exerts negative control of LDLR-mediated cholesterol uptake by inducing the expression of Idol (inducible degrader of the LDLR). Idol catalyzes the ubiquitination of LDLR and targets it for degradation [65].

Intracellular free cholesterol is converted into cholesteryl ester by acyl-Coenzyme A: cholesterol acyltransferase (ACAT). The function of ACAT2 in the hepatocyte is to provide esterified cholesterol for incorporation into verylow-density lipoprotein (VLDL), as well as to provide cholesteryl ester for cytoplasmic lipid droplets, a means for storage when liver cholesterol is abundant. Increased VLDL cholesteryl ester secretion occurs in livers of monkeys fed dietary cholesterol (reviewed in [140]). Mice, genetically engineered to lack Acat2 in both the intestine and the liver, were dramatically protected against hepatic neutral lipid (TG and cholesteryl ester) accumulation, in particular with elevated cholesterol diet. Inhibition of hepatic Acat2 can prevent dietary cholesterol-driven hepatic steatosis in mice [66].

Recently, Niemann-Pick C1-like 1 (NPC1L1) has been shown to play a pivotal role in cholesterol absorption [67]. Unlike mouse NPC1L1 protein that is predominantly expressed in the intestines, human and rat NPC1L1 is also abundantly expressed in the liver. Loss of NPC1L1 expression has been shown to protect against diet-induced fatty liver [68].

\section{Conclusion}

Nonalcoholic fatty liver disease (NAFLD) is a multi-factorial disorder with contribution of a variety of genetic and environmental factors that up till now no effective treatments exist for them. By poorly defined mechanisms, including free fatty acid and cholesterol accumulation accompanied by oxidative stress and inflammation, NAFLD may progress to the irreversible steatohepatitis (NASH) and further to cirrhosis or hepatocellular carcinoma. Herein, we review the major advances in the understanding of the pathogenic aspect of lipid and lipoprotein metabolism in NAFLD that could affect future therapeutic strategies. Currently, the only established treatment is weight loss since obesity underlies insulin resistance and NAFLD (reviewed in [141]). Caloric restriction reverses hepatic insulin resistance and steatosis in rats [142]. Fasting inhibits cholesterol and fatty acid synthesis and has protective effect on lipid metabolism [129]. Further, two different obesity-treatment drugs are currently on the market: orlistat, which reduces intestinal fat absorption, and sibutramine, an appetite suppressant (reviewed in [141]). 
NAFLD and cardiovascular disease share common risk factors, in particular disturbed lipid homeostasis accompanied by dyslipidemia. In patients with NAFLD, inhibition of cholesterol synthesis by statins alone [143] or in combination with antioxidants was shown beneficial [144]. However, the statin therapy shares common risks of drug failure in some individuals that can develop hepatoxicity or drug interactions [145]. Further on, inhibition of SREBP pathway represents another potential treatment for NAFLD. Inhibition of SREBP by a small molecule, betulin, decreased the biosynthesis of cholesterol and fatty acid [146]. Recent reports suggest a potential benefit of inhibiting intestinal cholesterol absorption by ezetimibe NPC1L1-inhibitor [147, 148]. Fenofibrates were also shown to decrease cholesterol absorption at the level of intestinal NPC1L1 expression [149].

Due to the complex multi-factorial nature of the disease, combined treatment may be needed to achieve better results. Indeed, dual inhibition of cholesterol absorption and synthesis and coadministration of ezetimibe/simvastatin offer a highly efficacious lipid-lowering strategy [150] and were shown to be effective and safe also in NAFLD patients [151].

In the complex pathology of NAFLD/NASH, the integrative approaches focusing on networks rather than on individual molecules, and applying environmental perturbations (diet, drugs, rhythm, etc.) in suitable animal models, can represent new venues towards predictive markers and successful therapies.

\section{Abbreviations}

ACAT: Acyl-coenzyme A cholesterol acyltransferase

ACC: Acetyl-CoA carboxylase

CETP: Cholesteryl ester transfer protein

CD-36: Cluster differentiation protein-36

ChREBP: Carbohydrate regulatory element binding protein

DGAT2: Diacylglycerol acyltransferase 2

ELOVL6: Family member 6, elongation of long-chain fatty acids

FASN: Fatty acid synthase

HL: $\quad$ Hepatic lipase

HSL: $\quad$ Hormone-sensitive lipase

IDL: Intermediate-density lipoprotein

Idol: Inducible degrader of the LDLR

LPL: $\quad$ Lipoprotein lipase

LDL: Low-density lipoprotein

LDLR: LDL receptor

L-PK: $\quad$ Liver-type pyruvate kinase

LXR: Liver X receptor

MTTP: Microsomal triglyceride transfer protein

NAFLD: Non-alcoholic fatty liver disease

NASH: Non-alcoholic steatohepatitis

PCSK9: Proprotein convertase subtilisin/kexin type 9

SCD1: Stearoyl-CoA desaturase

SREBP: Sterol regulatory element binding protein

TNF- $\alpha$ : Tumor necrosis factor $\alpha$

VLDL: Very-low-density lipoprotein.

\section{Acknowledgment}

This paper was supported by the Slovenian Research Agency Program Grant P1-0104.

\section{References}

[1] R. S. Rector, J. P. Thyfault, Y. Wei, and J. A. Ibdah, "Nonalcoholic fatty liver disease and the metabolic syndrome: an update," World Journal of Gastroenterology, vol. 14, no. 2, pp. 185-192, 2008.

[2] M. Lazo and J. M. Clark, "The epidemiology of nonalcoholic fatty liver disease: a global perspective," Seminars in Liver Disease, vol. 28, no. 4, pp. 339-350, 2008.

[3] I. Janssen, P. T. Katzmarzyk, W. F. Boyce et al., "Comparison of overweight and obesity prevalence in school-aged youth from 34 countries and their relationships with physical activity and dietary patterns," Obesity Reviews, vol. 6, no. 2, pp. 123-132, 2005.

[4] H. S. Park, J. H. Han, K. M. Choi, and S. M. Kim, "Relation between elevated serum alanine aminotransferase and metabolic syndrome in Korean adolescents," American Journal of Clinical Nutrition, vol. 82, no. 5, pp. 1046-1051, 2005.

[5] N. J. Barshop, C. B. Sirlin, J. B. Schwimmer, and J. E. Lavine, "Review article: epidemiology, pathogenesis and potential treatments of paediatric non-alcoholic fatty liver disease," Alimentary Pharmacology and Therapeutics, vol. 28, no. 1, pp. 13-24, 2008.

[6] G. Marchesini, M. Brizi, G. Blanchi et al., "Nonalcoholic fatty liver disease: a feature of the metabolic syndrome," Diabetes, vol. 50, no. 8, pp. 1844-1850, 2001.

[7] B. A. Neuschwander-Tetri and S. H. Caldwell, "Nonalcoholic steatohepatitis: summary of an AASLD Single Topic Conference," Hepatology, vol. 37, no. 5, pp. 1202-1219, 2003.

[8] R. K. Schindhelm, R. J. Heine, and M. Diamant, "Prevalence of nonalcoholic fatty liver disease and its association with cardiovascular disease among type 2 diabetic patients," Diabetes Care, vol. 30, no. 9, p. e94, 2007.

[9] P. Loria, A. Lonardo, S. Bellentani, C. P. Day, G. Marchesini, and N. Carulli, "Non-alcoholic fatty liver disease (NAFLD) and cardiovascular disease: an open question," Nutrition, Metabolism and Cardiovascular Diseases, vol. 17, no. 9, pp. 684-698, 2007.

[10] K. Musunuru, "Atherogenic dyslipidemia: cardiovascular risk and dietary intervention," Lipids, vol. 45, pp. 907-914, 2010.

[11] A. Kotronen and H. Yki-Järvinen, "Fatty liver: a novel component of the metabolic syndrome," Arteriosclerosis, Thrombosis, and Vascular Biology, vol. 28, no. 1, pp. 27-38, 2008.

[12] M. Hamaguchi, T. Kojima, N. Takeda et al., "Nonalcolholic fatty liver disease is a novel predictor cardiovascular disease," World Journal of Gastroenterology, vol. 13, no. 10, pp. 15791584, 2007.

[13] G. Targher, L. Bertolini, R. Padovani et al., "Prevalence of non-alcoholic fatty liver disease and its association with cardiovascular disease in patients with type 1 diabetes," Journal of Hepatology, vol. 53, no. 4, pp. 713-718, 2010.

[14] M. Ekstedt, L. E. Franzén, U. L. Mathiesen et al., "Longterm follow-up of patients with NAFLD and elevated liver enzymes," Hepatology, vol. 44, no. 4, pp. 865-873, 2006.

[15] R. L. McKimmie, K. R. Daniel, J. J. Carr et al., "Hepatic steatosis and subclinical cardiovascular disease in a cohort 
enriched for type 2 diabetes: the diabetes heart study," American Journal of Gastroenterology, vol. 103, no. 12, pp. 3029-3035, 2008.

[16] C. P. Day and O. F. W. James, "Steatohepatitis: a tale of two 'hits'?" Gastroenterology, vol. 114, no. 4, pp. 842-845, 1998.

[17] A. M. G. Cali, T. L. Zern, S. E. Taksali et al., "Intrahepatic fat accumulation and alterations in lipoprotein composition in obese adolescents: a perfect proatherogenic state," Diabetes Care, vol. 30, no. 12, pp. 3093-3098, 2007.

[18] C. J. Packard and J. Shepherd, "Lipoprotein heterogeneity and apolipoprotein B metabolism," Arteriosclerosis, Thrombosis, and Vascular Biology, vol. 17, no. 12, pp. 3542-3556, 1997.

[19] D. Lucero, V. Zago, G. I. López et al., "Does non-alcoholic fatty liver impair alterations of plasma lipoproteins and associated factors in metabolic syndrome?" Clinica Chimica Acta, vol. 412, no. 7-8, pp. 587-592, 2011.

[20] K. F. Petersen, S. Dufour, A. Hariri et al., "Apolipoprotein C3 gene variants in nonalcoholic fatty liver disease," New England Journal of Medicine, vol. 362, no. 12, pp. 1082-1089, 2010.

[21] B. Verggès, "New insight into the pathophysiology of lipid abnormalities in type 2 diabetes," Diabetes and Metabolism, vol. 31, no. 5, pp. 429-439, 2005.

[22] J. Kozlitina, E. Boerwinkle, J. C. Cohen, and H. H. Hobbs, "Dissociation between APOC3 variants, hepatic triglyceride content and insulin resistance," Hepatology, vol. 53, no. 2, pp. 467-474, 2011.

[23] M. Nakamuta, T. Fujino, R. Yada et al., "Impact of cholesterol metabolism and the LXR $\alpha$-SREBP-1c pathway on nonalcoholic fatty liver disease," International Journal of Molecular Medicine, vol. 23, no. 5, pp. 603-608, 2009.

[24] S. O. Olofsson, P. Stillemark-Billton, and L. Asp, "Intracellular assembly of VLDL: two major steps in separate cell compartments," Trends in Cardiovascular Medicine, vol. 10, no. 8, pp. 338-345, 2000.

[25] C. Namikawa, Z. Shu-Ping, J. R. Vyselaar et al., "Polymorphisms of microsomal triglyceride transfer protein gene and manganese superoxide dismutase gene in non-alcoholic steatohepatitis," Journal of Hepatology, vol. 40, no. 5, pp. 781786, 2004.

[26] R. Gambino, S. Bo, G. Musso et al., "Microsomal triglyceride transfer protein 493-T variant is associated with resistin levels and C-reactive protein," Clinical Biochemistry, vol. 40, no. 1617, pp. 1219-1224, 2007.

[27] M. Kjolby, O. M. Andersen, T. Breiderhoff et al., "Sort1, encoded by the cardiovascular risk locus $1 \mathrm{p} 13.3$, is a regulator of hepatic lipoprotein export," Cell Metabolism, vol. 12, no. 3, pp. 213-223, 2010.

[28] K. Musunuru, A. Strong, M. Frank-Kamenetsky et al., "From noncoding variant to phenotype via SORT1 at the $1 \mathrm{p} 13$ cholesterol locus," Nature, vol. 466, no. 7307, pp. 714-719, 2010.

[29] P. Linsel-Nitschke, J. Heeren, Z. Aherrahrou et al., "Genetic variation at chromosome 1 p13.3 affects sortilin mRNA expression, cellular LDL-uptake and serum LDL levels which translates to the risk of coronary artery disease," Atherosclerosis, vol. 208, no. 1, pp. 183-189, 2010.

[30] J. D. Horton, J. C. Cohen, and H. H. Hobbs, "Molecular biology of PCSK9: its role in LDL metabolism," Trends in Biochemical Sciences, vol. 32, no. 2, pp. 71-77, 2007.

[31] A. Zaid, A. Roubtsova, R. Essalmani et al., "Proprotein convertase subtilisin/kexin type 9 (PCSK9): hepatocyte-specific low-density lipoprotein receptor degradation and critical role in mouse liver regeneration," Hepatology, vol. 48, no. 2, pp. 646-654, 2008.

[32] H. N. Ginsberg, Y. L. Zhang, and A. Hernandez-Ono, "Regulation of plasma triglycerides in insulin resistance and diabetes," Archives of Medical Research, vol. 36, no. 3, pp. 232240, 2005.

[33] P. J. Voshol, G. Haemmerle, D. M. Ouwens et al., "Increased hepatic insulin sensitivity together with decreased hepatic triglyceride stores in hormone-sensitive lipase-deficient mice," Endocrinology, vol. 144, no. 8, pp. 3456-3462, 2003.

[34] I. J. Goldberg, R. H. Eckel, and N. A. Abumrad, "Regulation of fatty acid uptake into tissues: lipoprotein lipase- and CD36-mediated pathways," Journal of Lipid Research, vol. 50, pp. S86-S90, 2009.

[35] C. Z. Larter, M. M. Yeh, D. M. Van Rooyen et al., "Roles of adipose restriction and metabolic factors in progression of steatosis to steatohepatitis in obese, diabetic mice," Journal of Gastroenterology and Hepatology, vol. 24, no. 10, pp. 1658$1668,2009$.

[36] L. Zhu, S. S. Baker, W. Liu et al., "Lipid in the livers of adolescents with nonalcoholic steatohepatitis: combined effects of pathways on steatosis," Metabolism, vol. 60, pp. 1001-1011, 2010.

[37] L. P. Bechmann, R. K. Gieseler, J. P. Sowa et al., "Apoptosis is associated with CD36/fatty acid translocase upregulation in non-alcoholic steatohepatitis," Liver International, vol. 30, no. 6, pp. 850-859, 2010.

[38] V. Luangrath, M. R. Brodeur, D. Rhainds, and L. Brissette, "Mouse CD36 has opposite effects on LDL and oxidized LDL metabolism in vivo," Arteriosclerosis, Thrombosis, and Vascular Biology, vol. 28, no. 7, pp. 1290-1295, 2008.

[39] G. Endemann, L. W. Stanton, K. S. Madden, C. M. Bryant, R. T. White, and A. A. Protter, "CD36 is a receptor for oxidized low density lipoprotein," Journal of Biological Chemistry, vol. 268, no. 16, pp. 11811-11816, 1993.

[40] M. Febbraio, E. Guy, C. Coburn et al., "The impact of overexpression and deficiency of fatty acid translocase (FAT)/CD36," in Molecular and Cellular Biochemistry, pp. 193-197, Springer, Amsterdam, The Netherlands, 2002.

[41] C. Dorn, M.-O. Riener, G. Kirovski et al., "Expression of fatty acid synthase in nonalcoholic fatty liver disease," International Journal of Clinical and Experimental Pathology, vol. 3, no. 5, pp. 505-514, 2010.

[42] D. B. Savage, S. C. Cheol, V. T. Samuel et al., "Reversal of dietinduced hepatic steatosis and hepatic insulin resistance by antisense oligonucleotide inhibitors of acetyl-CoA carboxylases 1 and 2," Journal of Clinical Investigation, vol. 116, no. 3, pp. 817-824, 2006.

[43] G. Jiang, Z. Li, F. Liu et al., "Prevention of obesity in mice by antisense oligonucleotide inhibitors of stearoyl-CoA desaturase-1," Journal of Clinical Investigation, vol. 115, no. 4, pp. 1030-1038, 2005.

[44] P. Cohen, M. Miyazaki, N. D. Socci et al., "Role for stearoylCoA desaturase-1 in leptin-mediated weight loss," Science, vol. 297, no. 5579, pp. 240-243, 2002.

[45] J. M. Ntambi, M. Miyazaki, J. P. Stoehr et al., "Loss of stearoyl-CoA desaturase-1 function protects mice against adiposity," Proceedings of the National Academy of Sciences of the United States of America, vol. 99, no. 17, pp. 11482-11486, 2002.

[46] T. Matsuzaka, H. Shimano, N. Yahagi et al., "Crucial role of a long-chain fatty acid elongase, Elovl6, in obesity-induced insulin resistance," Nature Medicine, vol. 13, no. 10, pp. 1193 1202, 2007. 
[47] J. Araya, R. Rodrigo, P. Pettinelli, A. V. Araya, J. Poniachik, and L. A. Videla, "Decreased liver fatty Acid $\delta-6$ and $\delta-5$ desaturase activity in obese patients," Obesity, vol. 18, no. 7, pp. 1460-1463, 2010.

[48] J. G. Gormaz, R. Rodrigo, L. A. Videla, and M. Beems, "Biosynthesis and bioavailability of long-chain polyunsaturated fatty acids in non-alcoholic fatty liver disease," Progress in Lipid Research, vol. 49, pp. 407-419, 2010.

[49] I. Shimomura, Y. Bashmakov, S. Ikemoto, J. D. Horton, M. S. Brown, and J. L. Goldstein, "Insulin selectively increases SREBP-1C mRNA in the livers of rats with streptozotocininduced diabetes," Proceedings of the National Academy of Sciences of the United States of America, vol. 96, no. 24, pp. 13656-13661, 1999.

[50] M. Foretz, C. Guichard, P. Ferré, and F. Foufelle, "Sterol regulatory element binding protein-1c is a major mediator of insulin action on the hepatic expression of glucokinase and lipogenesis-related genes," Proceedings of the National Academy of Sciences of the United States of America, vol. 96, no. 22, pp. 12737-12742, 1999.

[51] R. Dentin, F. Benhamed, I. Hainault et al., "Liver-specific inhibition of ChREBP improves hepatic steatosis and insulin resistance in ob/ob mice," Diabetes, vol. 55, no. 8, pp. 21592170, 2006.

[52] J. Bricambert, J. Miranda, F. Benhamed, J. Girard, C. Postic, and R. Dentin, "Salt-inducible kinase 2 links transcriptional coactivator p300 phosphorylation to the prevention of ChREBP-dependent hepatic steatosis in mice," Journal of Clinical Investigation, vol. 120, no. 12, pp. 4316-4331, 2010.

[53] J. D. Horton, N. A. Shah, J. A. Warrington et al., "Combined analysis of oligonucleotide microarray data from transgenic and knockout mice identifies direct SREBP target genes," Proceedings of the National Academy of Sciences of the United States of America, vol. 100, no. 21, pp. 12027-12032, 2003.

[54] J. D. McGarry, G. P. Mannaerts, and D. W. Foster, "A possible role for malonyl CoA in the regulation of hepatic fatty acid oxidation and ketogenesis," Journal of Clinical Investigation, vol. 60, no. 1, pp. 265-270, 1977.

[55] S. C. Cheol, D. B. Savage, A. Kulkarni et al., "Suppression of diacylglycerol acyltransferase-2 (DGAT2), but not DGAT1, with antisense oligonucleotides reverses diet-induced hepatic steatosis and insulin resistance," Journal of Biological Chemistry, vol. 282, no. 31, pp. 22678-22688, 2007.

[56] X. X. Yu, S. F. Murray, S. K. Pandey et al., "Antisense oligonucleotide reduction of DGAT2 expression improves hepatic steatosis and hyperlipidemia in obese mice," Hepatology, vol. 42, no. 2, pp. 362-371, 2005.

[57] K. Yamaguchi, L. Yang, S. McCall et al., "Inhibiting triglyceride synthesis improves hepatic steatosis but exacerbates liver damage and fibrosis in obese mice with nonalcoholic steatohepatitis," Hepatology, vol. 45, no. 6, pp. 1366-1374, 2007.

[58] S. Turpin, A. Hoy, R. Brown et al., "Adipose triacylglycerol lipase is a major regulator of hepatic lipid metabolism but not insulin sensitivity in mice," in Diabetologia, pp. 146-156, Springer, Berlin, Germany, 2011.

[59] N. Stefan, H. Staiger, and H.-U. Haring, "Dissociation between fatty liver and insulin resistance: the role of adipose triacylglycerol lipase," in Diabetologia, pp. 7-9, Springer, Berlin, Germany, 2011.

[60] J. M. Brown, J. L. Betters, C. Lord et al., "CGI-58 knockdown in mice causes hepatic steatosis but prevents diet-induced obesity and glucose intolerance," Journal of Lipid Research, vol. 51, no. 11, pp. 3306-3315, 2010.
[61] M. S. Brown and J. L. Goldstein, "The SREBP pathway: regulation of cholesterol metabolism by proteolysis of a membrane-bound transcription factor," Cell, vol. 89, no. 3, pp. 331-340, 1997.

[62] D. J. Peet, B. A. Janowski, and D. J. Mangelsdorf, "The LXRs: a new class of oxysterol receptors," Current Opinion in Genetics and Development, vol. 8, no. 5, pp. 571-575, 1998.

[63] J. J. Repa and D. J. Mangelsdorf, "The liver X receptor gene team: potential new players in atherosclerosis," Nature Medicine, vol. 8, no. 11, pp. 1243-1248, 2002.

[64] P. J. Willy, K. Umesono, E. S. Ong, R. M. Evans, R. A. Heyman, and D. J. Mangelsdorf, "LXR, a nuclear receptor that defines a distinct retinoid response pathway," Genes and Development, vol. 9, no. 9, pp. 1033-1045, 1995.

[65] N. Zelcer, C. Hong, R. Boyadjian, and P. Tontonoz, "LXR regulates cholesterol uptake through idol-dependent ubiquitination of the LDL receptor," Science, vol. 325, no. 5936, pp. 100-104, 2009.

[66] H. M. Alger, J. Mark Brown, J. K. Sawyer et al., "Inhibition of acyl-coenzyme A: cholesterol acyltransferase 2 (ACAT2) prevents dietary cholesterol-associated steatosis by enhancing hepatic triglyceride mobilization," Journal of Biological Chemistry, vol. 285, no. 19, pp. 14267-14274, 2010.

[67] S. W. Altmann, H. R. Davis Jr., L.-J. Zhu et al., "NiemannPick C1 like 1 protein is critical for intestinal cholesterol absorption," Science, vol. 303, no. 5661, pp. 1201-1204, 2004.

[68] S. Yamagishi, K. Nakamura, T. Matsui, T. Sato, and M. Takeuchi, "Inhibition of intestinal cholesterol absorption by ezetimibe is a novel therapeutic target for fatty liver," Medical Hypotheses, vol. 66, no. 4, pp. 844-846, 2006.

[69] T. N. Tulenko and A. E. Sumner, "The physiology of lipoproteins," Journal of Nuclear Cardiology, vol. 9, no. 6, pp. 638-649, 2002.

[70] M. S. Brown and J. L. Goldstein, "A receptor-mediated pathway for cholesterol homeostasis," Science, vol. 232, no. 4746, pp. 34-47, 1986.

[71] M. Adiels, S. O. Olofsson, M. R. Taskinen, and J. Borén, "Overproduction of very low-density lipoproteins is the hallmark of the dyslipidemia in the metabolic syndrome," Arteriosclerosis, Thrombosis, and Vascular Biology, vol. 28, no. 7, pp. 1225-1236, 2008.

[72] M. Haidari, N. Leung, F. Mahbub et al., "Fasting and postprandial overproduction of intestinally derived lipoproteins in an animal model of insulin resistance," Journal of Biological Chemistry, vol. 277, no. 35, pp. 31646-31655, 2002.

[73] M. Zoltowska, E. Ziv, E. Delvin et al., "Circulating lipoproteins and hepatic sterol metabolism in Psammomys obesus prone to obesity, hyperglycemia and hyperinsulinemia," Atherosclerosis, vol. 157, no. 1, pp. 85-96, 2001.

[74] D. Singh, P. Sakhuja, V. Malhotra, R. Gondal, and S. Sarin, "Independent predictors of steatohepatitis and fibrosis in Asian Indian patients with non-alcoholic steatohepatitis," in Digestive Diseases and Sciences, pp. 1967-1976, Springer, Amsterdam, The Netherlands, 2008.

[75] I. Sugino, K. Kuboki, T. Matsumoto, E. Murakami, C. Nishimura, and G. Yoshino, "Influence of fatty liver on plasma small, dense LDL-cholesterol in subjects with and without metabolic syndrome," Journal of Atherosclerosis and Thrombosis, vol. 18, no. 1, pp. 1-7, 2011.

[76] F. G. S. Toledo, A. D. Sniderman, and D. E. Kelley, "Influence of hepatic steatosis (fatty liver) on severity and composition of dyslipidemia in type 2 diabetes," Diabetes Care, vol. 29, no. 8, pp. 1845-1850, 2006. 
[77] Y. Toyota, T. Yamamura, Y. Miyake, and A. Yamamoto, "Low density lipoprotein (LDL) binding affinity for the LDL receptor in hyperlipoproteinemia," Atherosclerosis, vol. 147, no. 1, pp. 77-86, 1999.

[78] K. Fujita, Y. Nozaki, K. Wada et al., "Dysfunctional very-lowdensity lipoprotein synthesis and release is a key factor in nonalcoholic steatohepatitis pathogenesis," Hepatology, vol. 50, no. 3, pp. 772-780, 2009.

[79] X. Q. Deng, L. L. Chen, and N. X. Li, "The expression of SIRT1 in nonalcoholic fatty liver disease induced by high-fat diet in rats," Liver International, vol. 27, no. 5, pp. 708-715, 2007.

[80] K. Kawaguchi, I. Sakaida, M. Tsuchiya, K. Omori, T. Takami, and K. Okita, "Pioglitazone prevents hepatic steatosis, fibrosis, and enzyme-altered lesions in rat liver cirrhosis induced by a choline-deficient L-amino acid-defined diet," Biochemical and Biophysical Research Communications, vol. 315, no. 1, pp. 187-195, 2004.

[81] K. Fujita, Y. Nozaki, K. Wada et al., "Effectiveness of antiplatelet drugs against experimental non-alcoholic fatty liver disease," Gut, vol. 57, no. 11, pp. 1583-1591, 2008.

[82] J. Björkegren, A. Beigneux, M. O. Bergo, J. J. Maher, and S. G. Young, "Blocking the secretion of hepatic very low density lipoproteins renders the liver more susceptible to toxin-induced injury," Journal of Biological Chemistry, vol. 277, no. 7, pp. 5476-5483, 2002.

[83] M. Raabe, M. M. Véniant, M. A. Sullivan et al., "Analysis of the role of microsomal triglyceride transfer protein in the liver of tissue-specific knockout mice," Journal of Clinical Investigation, vol. 103, no. 9, pp. 1287-1298, 1999.

[84] K. Minehira, S. G. Young, C. J. Villanueva et al., "Blocking VLDL secretion causes hepatic steatosis but does not affect peripheral lipid stores or insulin sensitivity in mice," Journal of Lipid Research, vol. 49, no. 9, pp. 2038-2044, 2008.

[85] X. Chang, H. Yan, J. Fei et al., "Berberine reduces methylation of the MTTP promoter and alleviates fatty liver induced by a high-fat diet in rats," Journal of Lipid Research, vol. 51, no. 9, pp. 2504-2515, 2010.

[86] D. Owens, "The extended postprandial phase in diabetes," Biochemical Society Transactions, vol. 31, no. 5, pp. 10851089, 2003.

[87] Q. Kang and A. Chen, "Curcumin suppresses expression of low-density lipoprotein (LDL) receptor, leading to the inhibition of LDL-induced activation of hepatic stellate cells," British Journal of Pharmacology, vol. 157, no. 8, pp. 13541367, 2009.

[88] J. L. Goldstein and M. S. Brown, "The LDL receptor," Arteriosclerosis, Thrombosis, and Vascular Biology, vol. 29, no. 4, pp. 431-438, 2009.

[89] M. Abifadel, M. Varret, J. P. Rabès et al., "Mutations in PCSK9 cause autosomal dominant hypercholesterolemia," Nature Genetics, vol. 34, no. 2, pp. 154-156, 2003.

[90] K. L. Donnelly, C. I. Smith, S. J. Schwarzenberg, J. Jessurun, M. D. Boldt, and E. J. Parks, "Sources of fatty acids stored in liver and secreted via lipoproteins in patients with nonalcoholic fatty liver disease," Journal of Clinical Investigation, vol. 115, no. 5, pp. 1343-1351, 2005.

[91] Y. D. I. Chen, A. Golay, A. L. M. Swislocki, and G. M. Reaven, "Resistance to insulin suppression of plasma free fatty acid concentrations and insulin stimulation of glucose uptake in noninsulin-dependent diabetes mellitus," Journal of Clinical Endocrinology and Metabolism, vol. 64, no. 1, pp. 17-21, 1987.

[92] J. Zhou, M. Febbraio, T. Wada et al., "Hepatic fatty acid transporter Cd36 is a common target of LXR, PXR, and
PPARgamma in promoting steatosis," Gastroenterology, vol. 134, no. 2, pp. 556-567, 2008.

[93] J. D. Browning and J. D. Horton, "Molecular mediators of hepatic steatosis and liver injury," Journal of Clinical Investigation, vol. 114, no. 2, pp. 147-152, 2004.

[94] A. J. Sanyal, C. Campbell-Sargent, F. Mirshahi et al., "Nonalcoholic steatohepatitis: association of insulin resistance and mitochondrial abnormalities," Gastroenterology, vol. 120, no. 5, pp. 1183-1192, 2001.

[95] J. Araya, R. Rodrigo, L. A. Videla et al., "Increase in longchain polyunsaturated fatty acid $n-6 / n-3$ ratio in relation to hepatic steatosis in patients with non-alcoholic fatty liver disease," Clinical Science, vol. 106, no. 6, pp. 635-643, 2004.

[96] I. Shimomura, H. Shimano, B. S. Korn, Y. Bashmakov, and J. D. Horton, "Nuclear sterol regulatory element-binding proteins activate genes responsible for the entire program of unsaturated fatty acid biosynthesis in transgenic mouse liver," Journal of Biological Chemistry, vol. 273, no. 52, pp. 35299-35306, 1998.

[97] J. Acimovic, A. Lövgren-Sandblom, K. Monostory et al., "Combined gas chromatographic/mass spectrometric analysis of cholesterol precursors and plant sterols in cultured cells," Journal of Chromatography B, vol. 877, no. 22, pp. 2081-2086, 2009.

[98] M. H. Oosterveer, A. Grefhorst, T. H. van Dijk et al., "Fenofibrate simultaneously induces hepatic fatty acid oxidation, synthesis, and elongation in mice," Journal of Biological Chemistry, vol. 284, no. 49, pp. 34036-34044, 2009.

[99] F. A. M. Nascimento, S. Barbosa-da-Silva, C. FernandesSantos, C. A. Mandarim-de-Lacerda, and M. B. Aguila, "Adipose tissue, liver and pancreas structural alterations in C57BL/6 mice fed high-fat-high-sucrose diet supplemented with fish oil (n-3 fatty acid rich oil)," Experimental and Toxicologic Pathology, vol. 62, no. 1, pp. 17-25, 2010.

[100] H. Ando, T. Takamura, N. Matsuzawa-Nagata et al., "The hepatic circadian clock is preserved in a lipid-induced mouse model of non-alcoholic steatohepatitis," Biochemical and Biophysical Research Communications, vol. 380, no. 3, pp. 684-688, 2009.

[101] T. P. Johnston, J. C. Baker, D. Hall, S. Jamal, W. K. Palmer, and E. E. Emeson, "Regression of poloxamer 407-induced atherosclerotic lesions in C57BL/6 mice using atorvastatin," Atherosclerosis, vol. 149, no. 2, pp. 303-313, 2000.

[102] L. Bünger, J. Forsting, K. L. McDonald et al., "Long-term divergent selection on fatness in mice indicates a regulation system independent of leptin production and reception," The FASEB Journal, vol. 17, no. 1, pp. 85-87, 2003.

[103] S. Horvat, L. Bünger, V. M. Falconer et al., "Mapping of obesity QTLs in a cross between mouse lines divergently selected on fat content," Mammalian Genome, vol. 11, no. 1, pp. 2-7, 2000.

[104] I. M. Stylianou, M. Clinton, P. D. Keightley et al., "Microarray gene expression analysis of the Fob3b obesity QTL identifies positional candidate gene Sqle and perturbed cholesterol and glycolysis pathways," Physiological Genomics, vol. 20, pp. 224232, 2005.

[105] I. M. Stylianou, J. K. Christians, P. D. Keightley et al., "Genetic complexity of an obesity QTL (Fob3) revealed by detailed genetic mapping," Mammalian Genome, vol. 15, no. 6, pp. 472-481, 2004.

[106] N. M. Morton, V. Densmore, M. Wamil et al., "A polygenic model of the metabolic syndrome with reduced circulating and intra-adipose glucocorticoid action," Diabetes, vol. 54, no. 12, pp. 3371-3378, 2005. 
[107] M. Simončič, S. Horvat, P. L. Stevenson et al., "Divergent physical activity and novel alternative responses to high fat feeding in polygenic fat and lean mice," Behavior Genetics, vol. 38, no. 3, pp. 292-300, 2008.

[108] S. Horvat, J. McWhir, and D. Rozman, "Defects in cholesterol synthesis genes in mouse and in humans: lessons for drug development and safer treatments," Drug Metabolism Reviews, vol. 43, no. 1, pp. 69-90, 2011.

[109] F. Foufelle and P. Ferré, "New perspectives in the regulation of hepatic glycolytic and lipogenic genes by insulin and glucose: a role for the transcription factor sterol regulatory element binding protein-1c," Biochemical Journal, vol. 366, no. 2, pp. 377-391, 2002.

[110] H. Shimano, J. D. Horton, I. Shimomura, R. E. Hammer, M. S. Brown, and J. L. Goldstein, "Isoform 1c of sterol regulatory element binding protein is less active than isoform 1a in livers of transgenic mice and in cultured cells," Journal of Clinical Investigation, vol. 99, no. 5, pp. 846-854, 1997.

[111] N. Yahagi, H. Shimano, A. H. Hasty et al., "Absence of sterol regulatory element-binding protein-1 (SREBP-1) ameliorates fatty livers but not obesity or insulin resistance in Lep/Lep mice," Journal of Biological Chemistry, vol. 277, no. 22, pp. 19353-19357, 2002.

[112] L. Abu-Elheiga, W. Oh, P. Kordari, and S. J. Wakil, "AcetylCoA carboxylase 2 mutant mice are protected against obesity and diabetes induced by high-fat/high-carbohydrate diets," Proceedings of the National Academy of Sciences of the United States of America, vol. 100, no. 18, pp. 10207-10212, 2003.

[113] K. Uyeda, H. Yamashita, and T. Kawaguchi, "Carbohydrate responsive element-binding protein (ChREBP): a key regulator of glucose metabolism and fat storage," Biochemical Pharmacology, vol. 63, no. 12, pp. 2075-2080, 2002.

[114] H. Yamashita, M. Takenoshita, M. Sakurai et al., "A glucoseresponsive transcription factor that regulates carbohydrate metabolism in the liver," Proceedings of the National Academy of Sciences of the United States of America, vol. 98, no. 16, pp. 9116-9121, 2001.

[115] S. Ishii, K. Ilzuka, B. C. Miller, and K. Uyeda, "Carbohydrate response element binding protein directly promotes lipogenic enzyme gene transcription," Proceedings of the National Academy of Sciences of the United States of America, vol. 101, no. 44, pp. 15597-15602, 2004.

[116] C. A. Nagle, E. L. Klett, and R. A. Coleman, "Hepatic triacylglycerol accumulation and insulin resistance," Journal of Lipid Research, vol. 50, pp. S74-S79, 2009.

[117] H. N. Ginsberg, Y.-L. Zhang, and A. Hernandez-Ono, "Regulation of plasma triglycerides in insulin resistance and diabetes," Archives of Medical Research, vol. 36, no. 3, pp. 232240, 2005.

[118] J. Pihlajamäki, H. Gylling, T. A. Miettinen, and M. Laakso, "Insulin resistance is associated with increased cholesterol synthesis and decreased cholesterol absorption in normoglycemic men," Journal of Lipid Research, vol. 45, no. 3, pp. 507-512, 2004.

[119] H. Gylling, M. Hallikainen, J. Pihlajamäki et al., "Insulin sensitivity regulates cholesterol metabolism to a greater extent than obesity: lessons from the METSIM study," Journal of Lipid Research, vol. 51, no. 8, pp. 2422-2427, 2010.

[120] P. Simonen, A. Kotronen, M. Hallikainen et al., "Cholesterol synthesis is increased and absorption decreased in nonalcoholic fatty liver disease independent of obesity," Journal of Hepatology, vol. 54, no. 1, pp. 153-159, 2011.

[121] M. Kainuma, M. Fujimoto, N. Sekiya et al., "Cholesterolfed rabbit as a unique model of nonalcoholic, nonobese, non-insulin-resistant fatty liver disease with characteristic fibrosis," Journal of Gastroenterology, vol. 41, no. 10, pp. 971980, 2006.

[122] N. Matsuzawa, T. Takamura, S. Kurita et al., "Lipid-induced oxidative stress causes steatohepatitis in mice fed an atherogenic diet," Hepatology, vol. 46, no. 5, pp. 1392-1403, 2007.

[123] M. Marí, F. Caballero, A. Colell et al., "Mitochondrial free cholesterol loading sensitizes to TNF- and Fas-mediated steatohepatitis," Cell Metabolism, vol. 4, no. 3, pp. 185-198, 2006.

[124] K. Wouters, P. J. van Gorp, V. Bieghs et al., "Dietary cholesterol, rather than liver steatosis, leads to hepatic inflammation in hyperlipidemic mouse models of nonalcoholic steatohepatitis," Hepatology, vol. 48, no. 2, pp. 474-486, 2008.

[125] G. S. Hotamisligil, "Inflammatory pathways and insulin action," International Journal of Obesity, vol. 27, supplement 3, pp. S53-S55, 2003.

[126] K. T. Uysal, S. M. Wiesbrock, M. W. Marino, and G. S. Hotamisligil, "Protection from obesity-induced insulin resistance in mice lacking TNF- $\alpha$ function," Nature, vol. 389, no. 6651, pp. 610-614, 1997.

[127] Y. Iimuro, R. M. Gallucci, M. Luster, H. Kono, and R. G. Thurman, "Antibodies to tumor necrosis factor alfa attenuate hepatic necrosis and inflammation caused by chronic exposure to ethanol in the rat," Hepatology, vol. 26, no. 6, pp. 1530-1537, 1997.

[128] M. Yin, M. D. Wheeler, H. Kono et al., "Essential role of tumor necrosis factor $\alpha$ in alcohol-induced liver injury in mice," Gastroenterology, vol. 117, no. 4, pp. 942-952, 1999.

[129] K. F. Tacer, D. Kuzman, M. Seliškar, D. Pompon, and D. Rozman, "TNF- $\alpha$ interferes with lipid homeostasis and activates acute and proatherogenic processes," Physiological Genomics, vol. 31, no. 2, pp. 216-227, 2007.

[130] K. Fon Tacer, D. Pompon, and D. Rozman, "Adaptation of cholesterol synthesis to fasting and TNF- $\alpha$ : profiling cholesterol intermediates in the liver, brain, and testis," Journal of Steroid Biochemistry and Molecular Biology, vol. 121, no. 3-5, pp. 619-625, 2010.

[131] A. Moreau, C. Téruel, M. Beylot et al., "A novel pregnane $\mathrm{X}$ receptor and S14-mediated lipogenic pathway in human hepatocyte," Hepatology, vol. 49, no. 6, pp. 2068-2079, 2009.

[132] T. Režen, V. Tamasi, A. Lövgren-Sandblom, I. Björkhem, U. A. Meyer, and D. Rozman, "Effect of CAR activation on selected metabolic pathways in normal and hyperlipidemic mouse livers," BMC Genomics, vol. 10, Article ID 1471, p. 384, 2009.

[133] D. J. Peet, S. D. Turley, W. Ma et al., "Cholesterol and bile acid metabolism are impaired in mice lacking the nuclear oxysterol receptor LXR $\alpha$," Cell, vol. 93, no. 5, pp. 693-704, 1998.

[134] J. J. Repa, G. Liang, J. Ou et al., "Regulation of mouse sterol regulatory element-binding protein-1c gene (SREBP1c) by oxysterol receptors, LXR $\alpha$ and LXR $\beta$," Genes and Development, vol. 14, no. 22, pp. 2819-2830, 2000.

[135] J. R. Schultz, H. Tu, A. Luk et al., "Role of LXRs in control of lipogenesis," Genes and Development, vol. 14, no. 22, pp. 2831-2838, 2000.

[136] G. Chen, G. Liang, J. Ou, J. L. Goldstein, and M. S. Brown, "Central role for liver X receptor in insulin-mediated activation of SREBP-1c transcription and stimulation of fatty acid synthesis in liver," Proceedings of the National Academy of Sciences of the United States of America, vol. 101, no. 31, pp. 11245-11250, 2004. 
[137] S. B. Joseph, B. A. Laffitte, P. H. Patel et al., "Direct and indirect mechanisms for regulation of fatty acid synthase gene expression by liver X receptors," Journal of Biological Chemistry, vol. 277, no. 13, pp. 11019-11025, 2002.

[138] S. Talukdar and F. B. Hillgartner, "The mechanism mediating the activation of acetyl-coenzyme A carboxylase- $\alpha$ gene transcription by the liver X receptor agonist T0-901317," Journal of Lipid Research, vol. 47, no. 11, pp. 2451-2461, 2006.

[139] J.-Y. Cha and J. J. Repa, "The liver X Receptor (LXR) and hepatic lipogenesis: the carbohydrate-response elementbinding protein is a target gene of LXR," Journal of Biological Chemistry, vol. 282, no. 1, pp. 743-751, 2007.

[140] L. L. Rudel, R. G. Lee, and P. Parini, "ACAT2 is a target for treatment of coronary heart disease associated with hypercholesterolemia," Arteriosclerosis, Thrombosis, and Vascular Biology, vol. 25, no. 6, pp. 1112-1118, 2005.

[141] T. D. Filippatos and M. S. Elisaf, "Combination drug treatment in patients with non-alcoholic fatty liver disease," World Journal of Hepatology, vol. 2, pp. 139-142, 2010.

[142] T. A. Bowman, S. K. Ramakrishnan, M. Kaw et al., "Caloric restriction reverses hepatic insulin resistance and steatosis in rats with low aerobic capacity," Endocrinology, vol. 151, no. 11 , pp. 5157-5164, 2010.

[143] M. Ekstedt, L. E. Franzén, U. L. Mathiesen, M. Holmqvist, G. Bodemar, and S. Kechagias, "Statins in non-alcoholic fatty liver disease and chronically elevated liver enzymes: a histopathological follow-up study:" Journal of Hepatology, vol. 47, no. 1, pp. 135-141, 2007.

[144] T. Foster, M. J. Budoff, S. Saab, N. Ahmadi, C. Gordon, and A. D. Guerci, "Atorvastatin and antioxidants for the treatment of nonalcoholic fatty liver disease: the st francis heart study randomized clinical trial," American Journal of Gastroenterology, vol. 106, no. 1, pp. 71-77, 2011.

[145] D. Rozman and K. Monostory, "Perspectives of the nonstatin hypolipidemic agents," Pharmacology and Therapeutics, vol. 127, no. 1, pp. 19-40, 2010.

[146] J.-J. Tang, J.-G. Li, W. Qi et al., "Inhibition of SREBP by a small molecule, betulin, improves hyperlipidemia and insulin resistance and reduces atherosclerotic plaques," Cell Metabolism, vol. 13, no. 1, pp. 44-56, 2011.

[147] M. Deushi, M. Nomura, A. Kawakami et al., "Ezetimibe improves liver steatosis and insulin resistance in obese rat model of metabolic syndrome," FEBS Letters, vol. 581, no. 29, pp. 5664-5670, 2007.

[148] M. Enjoji, K. Machida, M. Kohjima et al., "NPC1L1 inhibitor ezetimibe is a reliable therapeutic agent for non-obese patients with nonalcoholic fatty liver disease," Lipids in Health and Disease, vol. 9, p. 29, 2010.

[149] M. A. Valasek, S. L. Clarke, and J. J. Repa, "Fenofibrate reduces intestinal cholesterol absorption via PPAR $\alpha$ dependent modulation of NPC1L1 expression in mouse," Journal of Lipid Research, vol. 48, no. 12, pp. 2725-2735, 2007.

[150] A. C. Goldberg, A. Sapre, J. Liu, R. Capece, and Y. B. Mitchel, "Efficacy and safety of ezetimibe coadministered with simvastatin in patients with primary hypercholesterolemia: a randomized, double-blind, placebo-controlled trial," Mayo Clinic Proceedings, vol. 79, no. 5, pp. 620-629, 2004.

[151] T. Ábel, J. Fehér, E. Dinya, M. G. Eldin, and A. Kovács, "Safety and efficacy of combined ezetimibe/simvastatin treatment and simvastatin monotherapy in patients with non-alcoholic fatty liver disease," Medical Science Monitor, vol. 15, no. 12, pp. MS6-MS11, 2009. 

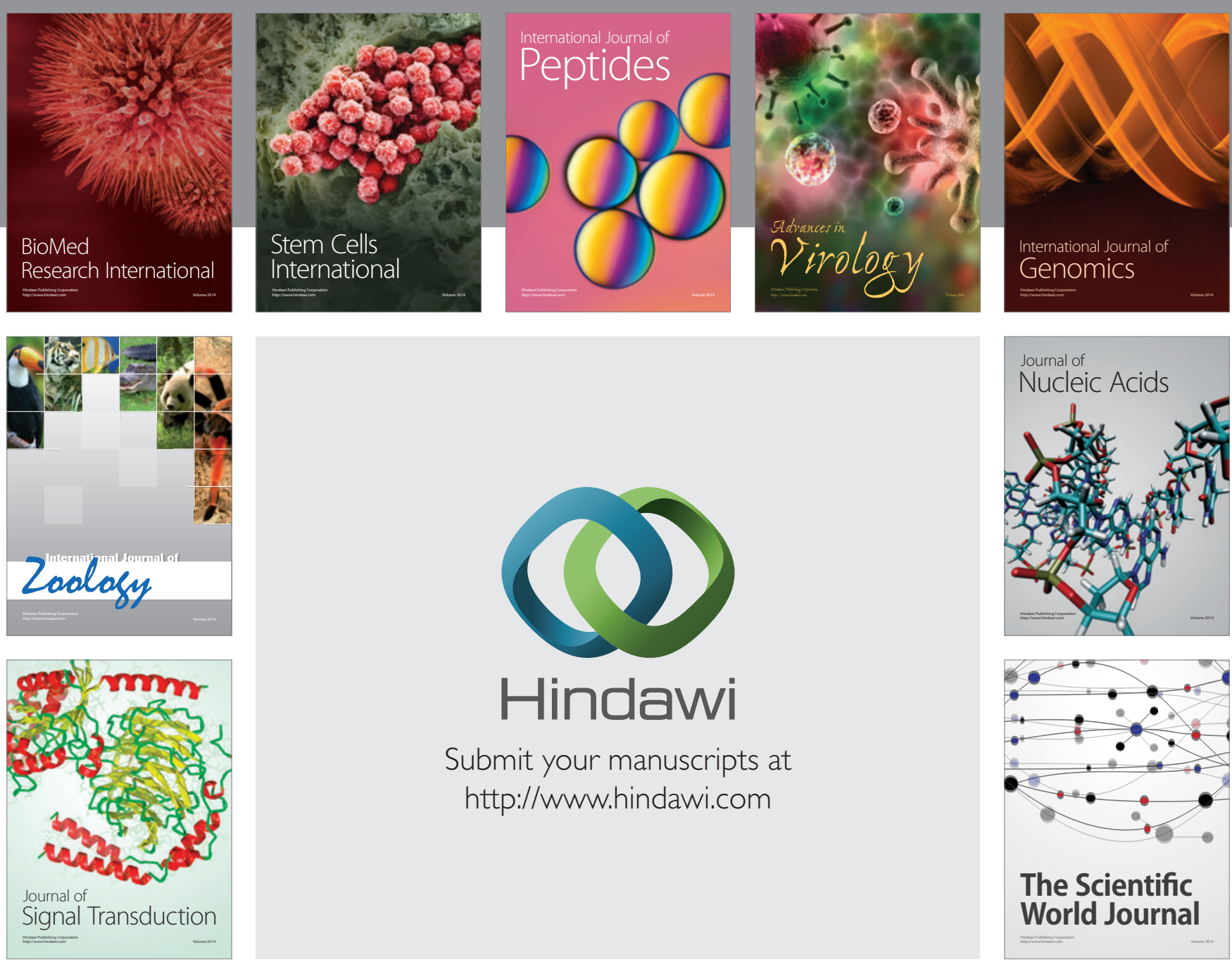

Submit your manuscripts at

http://www.hindawi.com
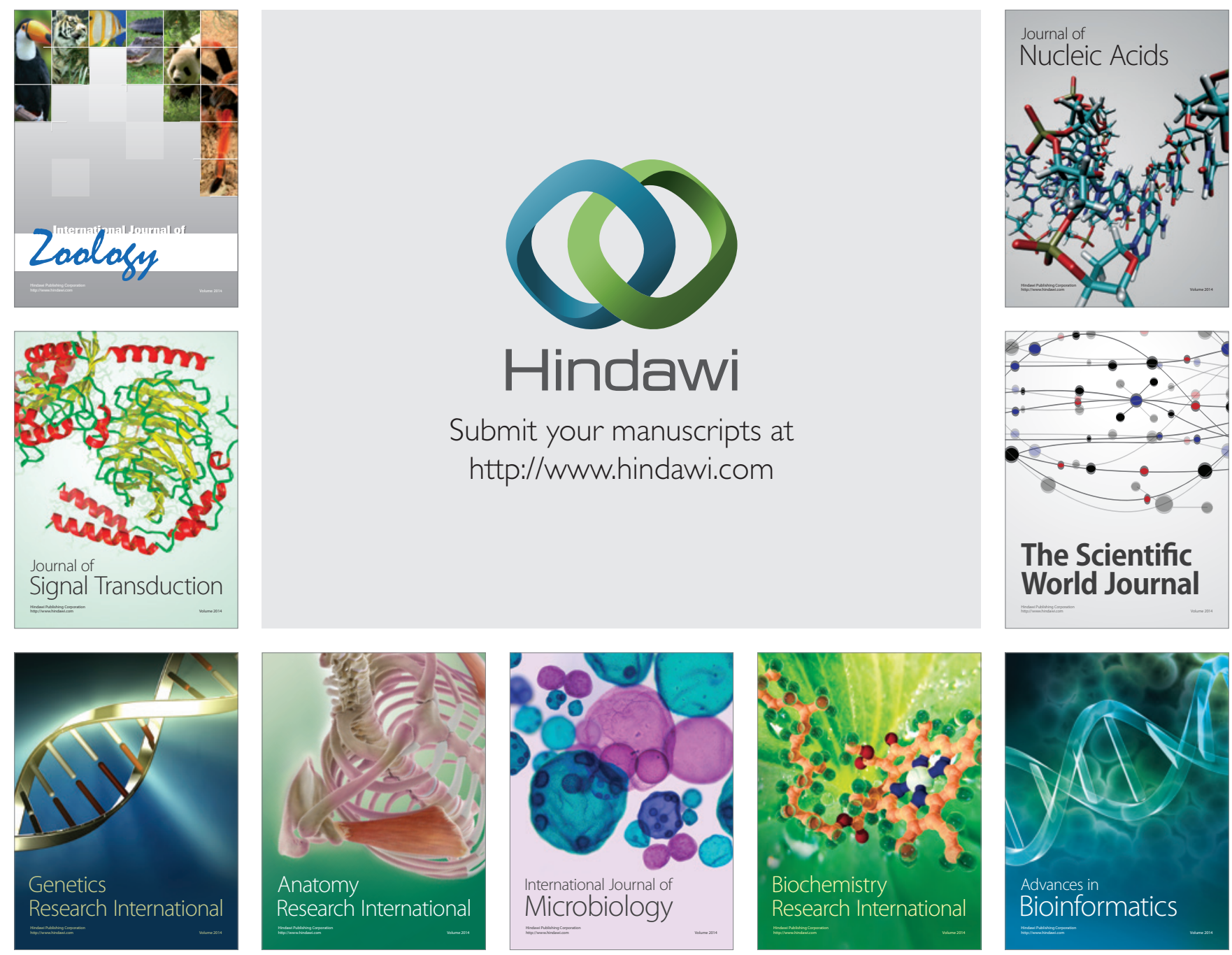

The Scientific World Journal
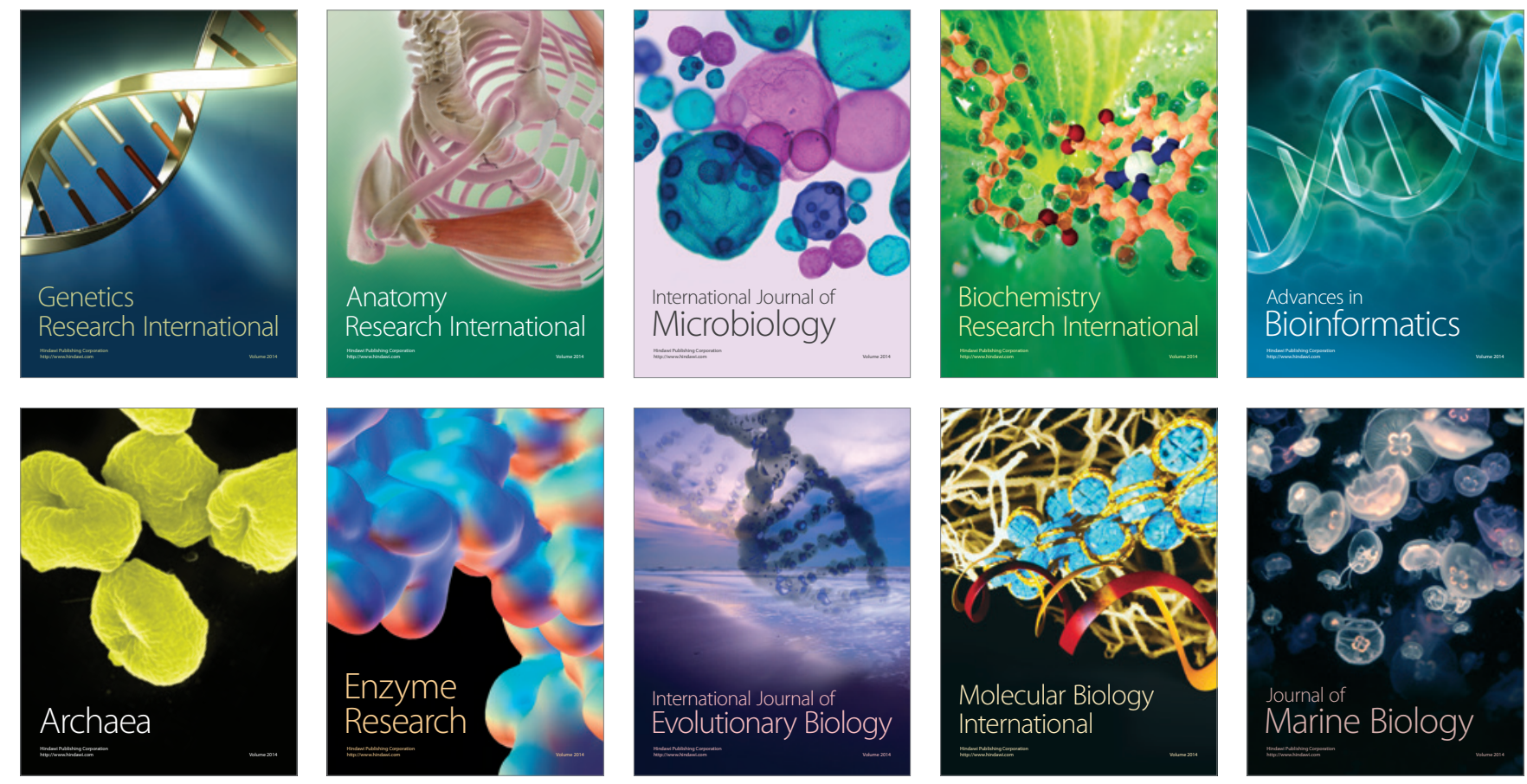